\title{
Mystery and the Body: Provoking a Deep Ecology through the Situated Bodies of Teacher Candidates
}

\author{
JEANNE ADELE KENTEL \\ Brock University (Canada) \\ DOUGLAS KARROW \\ Brock University (Canada)
}

\begin{abstract}
This paper examines the complexities of being trapped in a space of technocratic approaches to teacher education. We begin to unfold possibilities of permeating the boundaries amassed by Technicity through the conjoinder of mystery and the body. The binaries of perceptual and conceptual knowing are problematized through our admission of the pervading dualisms in education despite monistic efforts. As an antidote to "technocratic" training, place-based experiences were provided in order to foreground the body as a conduit to knowing while maintaining mystery, create spaces for reflective practice, enliven the imagination, and more holistically assist teacher candidates in becoming teachers. Ways of engaging the bodymind in order to bring about a broader, critical educative focus in teacher education are discussed.
\end{abstract}




\section{The Belly of the Lion}

Some time ago we considered and reconsidered the tensions of the space in which we existed in a teacher education program, that is, The Belly of the Lion. Through discussion of the complexities of being trapped in a space of Technicity ${ }^{1}$ we surmised that, "merging the mysterious nature of science with the unfamiliar landscape of the physical offers promise for a more embodied pedagogy, which provocatively initiates imaginative engagement" (Karrow and Kentel 2005, 25) and further suggested:

Teacher education that can become more existentially attuned by considering, for example, the subverted binaries of mystery and the body, moves toward resuscitating a way of being that is more ontologically, culturally, and ecologically sensitive.

In light of this, we recently attempted to provide experiences for teacher candidates, which create a space for mystery and the body outside the belly of Technicity. In speaking of mystery and the body we wish to underscore the complexity of these traditionally subverted binaries. Mystery/knowledge and body/mind are common modern binaries for understanding experience. The latter of each pair tends to dominate much discussion in education circles especially in academic settings where knowledge and mind are privileged over mystery and body (Cheville 2001, 2005). We live during a time when knowledge dominates educational aims and goals i.e. students must be prepared to live in a global knowledge-based economy where certain awareness is required in a world that is becoming increasingly vocational and credentialed (Jacobs 2004). As such, extensive effort is devoted within educational institutions to prepare students in this fashion. In our pursuit of knowledge, mystery must yield its unfathomable secrets. The same can be said of the body / mind binary, a dichotomy Varela, Thompson, and Rosch $(1991,28)$ call a habit of mindlessness:

It is a matter of simple experience that our mind and body can be dissociated, that the mind can wander, that we can be unaware of where we are and what our body or mind are doing. But this situation, this habit of mindlessness, can be changed. Body and mind can be brought together. We can develop habits in which mind and body are fully coordinated.

The mind has traditionally been viewed as the conduit to obtain knowledge much to the detriment of embodied knowledge or the body's way of knowing, as it is more commonly referred. Similarly, whilst there may be a tendency to acknowledge the complex (i.e. entwined) nature of mystery and the body, blurring of the two has been historically irresistible because knowledge has been equated with the mind. Therefore, we wish to consider mystery and the body somewhat independently, although at times we may too slip into their common alliance. Our focus on mystery is for the sake of rejuvenating a sense of the mysterious-the wonder, awe and passion we all 
experience when engaging with phenomena. The complete subversion of mystery for the sake of knowledge has created an aesthetic, unimaginative, and spiritual vacuum, which some have claimed to be the most significant existential challenge we face (Heidegger 1962; Nietzsche 1883-85/1993; Thomson 2001). We argue a more informed reality necessitates recognition of the delicate balance implied between these construed binaries. To employ the metaphor of a sojourn, "mystery is the constancy of departure; knowledge the approximation of arrival" (Karrow 2006, 202). Each is essential to the learning/teaching dynamic. Arguably, this could be achieved through the mind/body binary as long as each is equally considered; however, like Varela et al. we observe this not to be the case as most learning continues to be organized, facilitated, and structured through the mind.

These distinctions between mystery and the body may seem protracted but their clarification is necessary. Henceforth, we describe our movement from ideas about learning in teacher education to our first attempt at putting into practice an engaging, embodied pedagogy through the merging of science and physical education curricula. The pairing of these subjects may seem unusual; however, they quintessentially symbolize the great divide between mystery/knowledge and body/mind and the possibility of full coordination. In this paper we attempt to disrupt the manner that modern schooling has displaced the body as a site for learning through discussion of an uncomplicated place-based learning experience where teacher candidates were asked to consider bodily ways of knowing by focusing on perception. We further consider the possibilities for teacher education programs to embrace embodied knowing, situated within place, while vitalizing the imagination as a precursor to deeper connections with life and the earth, and provoking care for the earth through human identification with plants and animals, namely, Deep Ecology.

\section{Modern Schooling and the Displacement of the Learning Body}

\section{The Omnipresent Desk and the Absence of Pedagogy}

The mind overshadowing the body is a common characteristic of educational practice: Children have been made to sit in desks for years in efforts to educate their minds. Time may be taken for some movement, but more often it takes the form of physical training rather than an authentic educational union of body and mind. Mind/body dualism is further perpetuated by administrative pressures for academic achievement and attempts for a quick fix in the literacy challenges that educators face. As a result, the desk is the sole source of corporeality in the education of the mind; "the desk" is an integral part of the problem of the situated body. 
Were children given the choice, it is doubtful they would sit in desks all day. Yet year after year this is an expectation of children as young as five years of age. This sort of spatial confinement can negate students' "becoming" (Sawada and Caley 1990), their way of living in the world. We, as educators, often become entrapped by a pedagogical mode of constricting, restricting, and essentially stifling the imagination of children. The pedagogical relationship iconicized by the desk is omnipresent restricting movement within classrooms. Children are frequently lost in political agendas with schooling simulating training rather than educating. There is an absence of pedagogy engaging the body through mystery (Kentel 2001). Ped paidos (child), and ago ago (to lead) are overcome by the need to direct or the drive to accomplish. This is ever present in the way even an area such as physical education is regularly approached. It is not an education of the mind and body per se, but an exercise in physical activity. Movement understanding is not a priority; subsequently physical education becomes physical activity, further compartmentalizing the educational experience. Saffici $(1999,140)$ contends, "Physical educators need to be equipped with understanding of the world beyond the gym and playing field". When education is compartmentalized, the possibility that children will leave the room for physical activity, only to return to sit in desks for the remainder of the day, is heightened.

Compartmentalization also poses difficulties and challenges for science educators as science has traditionally been taught within a classroom or lab with desks or lab tables as the primary sites for learning. That learning could also occur in sites beyond the classroom has been recognized for years in the Outdoor Education movement. Regardless, within science education, because of this preoccupation with the re-presentation of cultural knowledge at the "desk", opportunities to engage a bodily way of knowing beyond the presence of the desk are rare. Albeit some such as Karen Meyer (2000) are challenging these traditional avenues of knowledge advocating place-based or site-based experiences outside the typical classroom where students learn through direct and immediate bodily experiences.

What is the pedagogical interest served by desks? Are they mere inanimate objects, or are they the "natural" technological footprints of mind/body dualism? Conceivably, the fundamental quandary is not the desks at all, but rather the absence of pedagogy in the way that children are confined to them, as identified nearly a century ago (Welton 1912). The absence of pedagogy manifested in the presence of the desk must be understood within the presence of pedagogy and the absence of the desk. The presence of the body manifests itself in the absence of the desk, yet even when attempts are made to move learning beyond classroom walls, the desk still has an overwhelming presence (see Figure 1). 


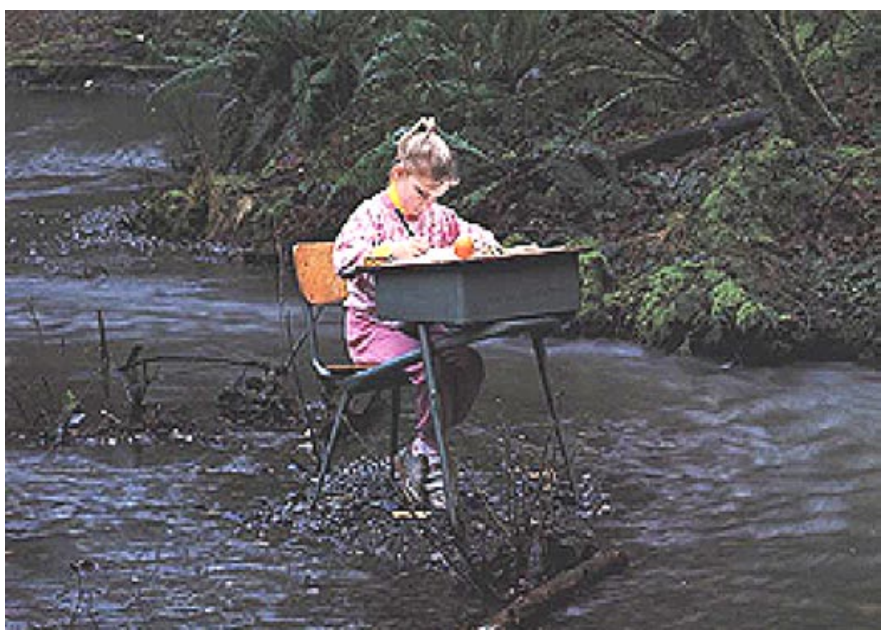

Figure 1. Pedagogy and the desk (Canadian Wildlife Federation, 1985)

This image could be considered from several perspectives. For example, it may suggest that learning occurs out of doors; learning represented by the desk and place represented by nature. A second glance, however, might suggest that the presence of the desk is so prominent that the wealth of sensory experience made available in the natural setting is overlooked, i.e. our conceptions of learning are so focused on the desk that children endure a neglect of the body and disconnect with the earth. In addition, governmental organizations measure what children know with their minds and disregard what they know with their bodies, perpetuating further dualistic discourse. It has even penetrated discourses where an attempt to avoid distinctions is made by making distinctions. These recursive absences and presences (Smith 1999) require a shift to a cohesive presence of the body with the presence of the desk. If mind and body are conjoined in an integrated whole, why do we continue to separate them in our conversational explorations? Nietzsche $(1974,322)$ offers this insight:

We do not belong to those who have ideas among books, when stimulated by books. It is our habit to think outdoors - walking, leaping, climbing, dancing, preferably on lonely mountains or near the sea where even the trails become thoughtful. Our first questions about the value of a book, of a human being, or a musical composition are: Can they walk? Even more, can they dance?

Confinement to a desk is a celebration of the static body - a celebration that need not have the dominance that it does. Despite theoretical support for kinaesthetic intelligences (Gardner 1993), this view that movement is distinct from learning continues to dominate: The classroom is for the mind; the outdoors, playing field, or gymnasium is for the body. The empty playing 
field and the occupied desk are familiar sights. How might the field become more populous (present)? How might the desk become less prevalent (more absent)? How might places of nature contribute to the overall education of children? How might the habits of educating the mind in isolation be reversed?

Whitehead $(1929 / 1962,10)$ offers insights into the difficulty of inanimate foci:

There is a proverb about the difficulty of seeing the wood because of the trees. That difficulty is exactly the point which I am enforcing. The problem of education is to make the pupil see the wood by means of the trees. The solution which I am urging, is to eradicate the fatal disconnection of subjects which kills vitality of our modern curriculum.

The desk, an inanimate object, springs forth from materiality of the tree. We contend that moving from the desk to other places of learning is one way of moving from conceptual to perceptual experiences for students. Although many classroom teachers accomplish this feat, we question the lack of presence of perception in teacher education programs. Teacher candidates may be told about the significance of the perceptual but are they provided with experiences that provoke these ways of knowing in their own university encounters? We argue that one way to increase perceptual ways of knowing is through placebased learning. Although classrooms and desks could be "sites" and "places" for perceptual experiences, our use of these terms refers to those learning experiences arranged out of doors where ecological encounters can occur.

\section{Deep Ecology: \\ Provoking the Body and Imagination through Place-Based Education}

The relationship between embodied knowing, the perceptual, place and education, and the imagination is a complex yet holistic relationship. We see the relationship in the following way. Taken together these elements of imaginative learning begin to enact Deep Ecology.

Place-based approaches to education aim to situate students within specific localities where certain economic, social, political and historical features are summoned within the learning experience. While this comprises a more objective component, the subjective element of place-based education strives to summon those personal feelings and emotions that evoke certain places. The intersection of the objective with the subjective comprises what we refer to as the locale (Karrow 2006). Regardless, to more realistically evoke the essential balance between perceptual and conceptual learning beyond a modern classroom, place-based education has been advocated.

The link between place-based education, perceptual or embodied knowing and the imagination is thus. As place-based education situates 
the body and the mind evoking a clear existential relationship, the capacity of the imagination is more fully engaged. According to Sloan (1983), imagination is that which is stimulated during the interplay between the perceptual (feeling) and the conceptual (thinking) through the mediation of human agency or will. It is this capacity of imagination that we equate with a Deep Ecology. As imagination mediates between thinking and feeling realms, through human will, the binary distinctions that dominate modern thought ease. Imagination is a precondition to Deep Ecology; as the fate of human imagination continues to be debated (Kearney 1998), the possibility of practicing Deep Ecology becomes more difficult yet more important as is the development of the ecological imagination (Jardine 1998).

\section{Enacting a Deep Ecology for Teacher Candidates}

The purpose of this inquiry is to explore teacher candidates' responses to a direct and immediate experience where existential learning is fostered outside the traditional context of the classroom. Opportunities for these students to exercise both perceptual and conceptual capacities will be provided in a way that adheres to the tenets of existential phenomenology. By engaging in this way with phenomena, it is our hope that students will slowly become aware of other avenues to understanding, consider how more dominant epistemologies subvert other ways of knowing, and begin to experience how mystery and knowledge each complement one another. We surmise that such understandings, provided by repeated experiences of this nature - that is interaction with the earth, mystery, and the sensing body-would slowly stimulate within our students the ability to envision other possibilities beyond those increasingly prescribed by instrumental thinking.

\section{Focus Question}

What understandings are made possible through place-based perceptual experiences, which comprise the imaginative engagement of body and the mind in teacher education?

To consider this question we pursue ways in which teacher candidates' science and physical education methods courses might be integrated so that traditional mind/body binaries can be deconstructed to foster a more thoughtful, meaningful, critical, and imaginative education experience.

\section{The Matter of Method}

Mixed methods of interpretive inquiry (Gadamer 2002; Merleau-Ponty 1968) are used to understand the personal accounts of teacher candidates. The perceptions of the students as well as the methodological encounter with the texts are 
unknown paths. Dwelling in the non-knowing mystery is an affecting place-not like a secret waiting to be uncovered, but rather a conversation waiting to happen. This is what compels us to go on thinking and talking about what we think we know, despite the mystery of existence inspiriting us. We interpret and reinterpret the texts hermeneutically keeping the movement conversation open. The new conversations lead to new understandings, new methods of conversing, or perhaps more appropriately, new ways of engaging in discourse.

In our encounter with the data we rely significantly on the work of Merleau-Ponty (1968) who argues that the 'body subject' is frequently underestimated by philosophers who regard the body as something to be transcended by the power of the mind. Although perception itself might be regarded as primarily cognitive, Merleau-Ponty's view is that understanding occurs through an embodied relation to the world. Our contention is that bodily experience is both cognitive and physical and as such this embodied relation is prominent in the way we locate the inquiry as well as in the way we interact with the data. Richardson (1992), and the provocative work of Kamler (1998) inspired us to display the data in a poetic way. $\operatorname{Leggo}(2004,2)$ observes that poetry is an invitation "to breathe, to attend, to slow down, to embrace the healing of body and spirit and imagination". Thus, presenting the data aesthetically is a way of living poetically and enlivening our imaginations as researchers.

\section{Participants}

The participants are eight teacher education students, two male and six female. This paper focuses upon entries from four of the students. The students were in their fourth year of a five-year concurrent program (BPE/BEd) in the province of Ontario. All the names of the participants have been changed in order to ensure anonymity.

\section{Setting and Events}

The inquiry occurred within the space of a unique health and physical education course in a teacher education program. More than half of the time allotted occurred outside of the university classroom setting. Unlike "technocratic" training (Giroux 1988; Thomson 2001), these place-based experiences create spaces for reflective practice, foreground the body as a conduit to knowing while maintaining mystery, enliven the imagination, and more holistically assist teacher candidates in becoming teachers. Each week the students entered online reflections, which focused upon some aspect of the place-based- experience. This paper focuses upon one session, which occurred in a natural park setting prior to spring. The session was developed to provide an integrated learning experience (i.e. science and physical education) exploring mystery and the body through perceptual ways of knowing. 
Following the nature walk, the participants were asked to reflect on a particular encounter with something (living or non-living) along the way and to describe it in full detail using all of their senses. They responded to this task in written format. One student submitted a supplementary illustration of her experience. As well, the following four questions were asked of the participants, which they responded to online: (a) How might description lead to further understandings of phenomena? (b) How might explanation preclude or foreclose understandings of phenomenon? (c) In what way(s) might description enliven the imagination? and (d) How might imagination lead to further understandings? The responses were compiled, displayed, and analyzed through a hermeneutical encounter with the written texts.

\section{The Findings}

In keeping with our intent to provoke imaginative engagement with the texts we contend that, "poetry is a place where the unimaginable can be imagined" (Leggo 2004, 10) and as such we repositioned the participants' entries in a poetic format. Ellipsis points are used to connect texts and brackets are used to insert words where necessary providing clarity. Typos in the online texts have been corrected to improve the flow of the poetic form. The transcript poems are arranged according to living and non-living excerpts provided by the participants.

Sharyn begins by describing what fascinates her about the moss:

the moss ... grows

facing one direction ...

forms on surfaces

such as rocks and logs...

green in colour and have a moist texture,

if you peel it up at the side,

you will see that the underneath is brown,

almost like a soily texture.

It is interesting because it does not seem to stem from anywhere, there are no visible roots shooting into the ground like other plants.

When feeling it, especially now, it is cold and damp, in the summer

it dries out.

Sometimes it can be removed quite easily, and other times it seems very attached to objects.

Fascinating, isn't it? 
Sharyn relates the characteristics of the moss to life experience. The moss can be easily removed or attached to the other. The moss responds to the environment around it and becomes moist when exposed to moisture and dry when exposed to the hot sun. Is this what learning is? Do learners respond to the conditions of the environment they are exposed to? In what ways are learners rooted? Or are learners like the moss, which becomes attached with no visible signs of being rooted?

Sharyn added that, "description can lead to further understandings of phenomena when paired together with the senses." Her description of the moss forming and growing on the surface is intriguing when considered in light of the nature of life. The etymology of surface is from the Old French sur meaning "above" and face, which is derived from the Latin facies meaning, "appearance, form, figure," and secondarily "visage, countenance." How moss forms on the surface is how it appears to the human eye. This visage or appearance is transformed when one begins to look underneath as Sharyn did with the moss only to discover that despite the lack of roots and the appearance of surface growth, the moss itself can become attached without roots.

During the nature walk Sibel took notice of the sap on the trees:

notice ... the sap

on the tree...

sticky to touch....

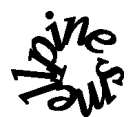

Sibel encountered nostalgia as she recalled an early elementary school field trip.

[The sap] looked as though it would be sticky because of its thick appearance. It made the bark on the tree darker in the spots that it covered. I found it interesting to describe how it worked. I remember in grade two going to pioneer village and we were taught how maple syrup was made. I can still remember the trip today so obviously it was interesting enough that it had a lasting impression on me.

The senses evoke memory. As a young child Sibel wondered what the sap was like and used her taste buds to determine its sweetness. But now she admits, "I didn't taste it for obvious reasons." Often we stifle the natural inquisitiveness of children, their very sense of wonder by providing them with answers to questions they have not yet asked. The senses are integral to the way in which we relate to the world. Sibel adds, "Using my senses to describe it was something that I really don't do all that often. Being in the university setting we really aren't encouraged to use our senses in describing things." The sap that she imagined to be sticky, when touched by a sensing body, would touch her back. Her description of the sap is a way of "writing language back into the land" (Abram 1996, 273).

Jenn focused on the mud and broken trees during her walk: 
$\operatorname{mud} \ldots$

sign of the changing season ...

things ...

thaw out

groupings of broken trees ...

in rough shape...

not looking strong

Observing the changing seasons, indicated by the frozen earth thawing to a pliable texture, is a metaphor for transformation. The warmth of the sun on the frozen ground allows its very constitution to be changed. The mud; however, is messy for a time until the sun once again dries it up. Jenn adds that, "Description could enliven the imagination by making one think more deeply about something, seeing something past its surface value." This "deeper thinking" allows one to consider other possibilities beyond the obvious or literal. Her interest and fascination with a group of damaged trees is also telling. After walking through a particularly vital section of the forest boasting large, healthy, and indigenous trees, we came upon an open area that had obviously been cleared during colonization. Subsequent growth did not benefit by the sheltering effect of more mature trees. For new beings to survive they require the support, shelter and guidance of those before. Left to their own, they are vulnerable to the ravages of storm, ice, wind, and such. This homogeneity of space perfectly symbolizes the bland, mass; one size fits all hegemony of modernity. Education must create spaces for generations of learners to interact, to share learning, to embrace mystery and reveal in the wonder, the curiosity, the awe of phenomena. Place-based education could allow for such interaction if we openly engaged the wisdom of our elders.

Karyn focused on the mud in her response. In lieu of using words to describe her encounter with nature she elected to illustrate her encounter (see Figure 2, next page). Karyn relies not only on her ability to draw, to use a pencil to lay down an image, but also on the sensing ability of her vision and her capacity to recall her experience on the walk. What is particularly salient about this text is the way in which it can evoke human emotion and a sense of wonder in the viewer. When did the deer pass? How old was it? How long has it been since the leaves fell upon it? Where is the next print? How is mystery encountered in the body?

\section{Emerging Thoughts}

Reflecting on the student entries and responses, a recurring theme is the notion of "presence" and "absence". Within several student responses there are allusions to this. For example, mud is the absence of frost on the surface of the earth, the presence of the sprouting plants among the life- 


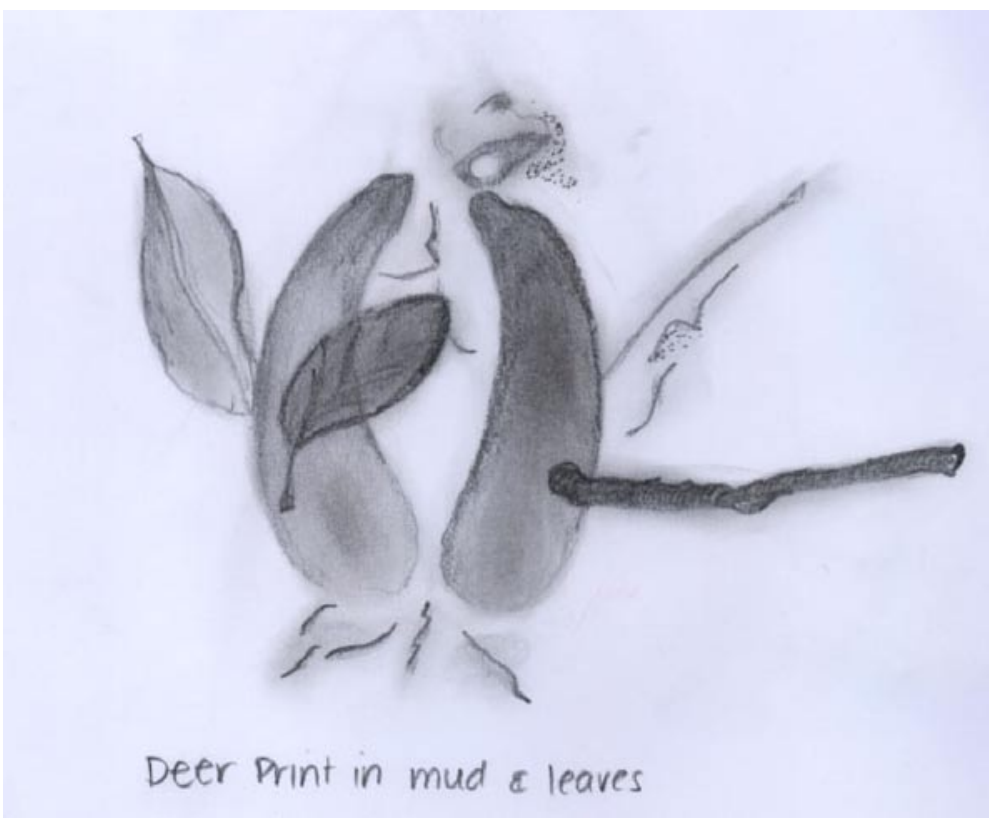

Figure 2. Deer print in mud and leaves

less broken branches, the sound of the crackling leaves among the silence. With little prompting, the participants engaged with the natural environment in an imaginative and thought provoking way and from this, notions of absence and presence emerged. Provided with opportunities to engage with natural phenomena in ways that don't exclusively privilege what is present before them, with students falling into the habit of equating this solely with modern notions of $t$ ruth, i.e., that which is present $=$ truth, we were able to maintain for them other ways of relating with the natural world. In other words, they could experience the mystery of how we come to understand phenomena around us in a way the maintains the being's beingness, whether is be the undisturbed "ice" and "mud", "sound" and "silence", or "branch" and "root". Each of these harbors within it the capacity to be present, available to us for knowing, while maintaining the possibility for presence through absence. This is the notion of mystery we wish to preserve and maintain. The question that remains is whether or not they are aware that they are naturally attuned to these capacities. Are they aware of the cognitive tools or bodily sensibilities they are calling upon in order to respond to their experiences or are these sorts of responses part of the taken-for-granted capacities of human living? Entities can be revealed and concealed, despite what more commonly occurs today: the exhaustive and aggressive revealing of an entire entity's capacity. Perhaps our students are responding to the ancient metaphysic, Physis, ${ }^{2}$ on some subconscious 
or intuitive level. Our existential learning experiences seemed to trigger this association so they come to appreciate the mystery behind how there is any(thing) to know at all and in that knowing there is always preserved the future capacity for knowing by languishing in mystery.

\section{Future Possibilities for Teacher Candidates From Trees to Desks and Back Again}

The dynamic sway of existential phenomenology is at play when the mind and body are equally evoked. We perceive directly through the immediacy of the body while the mind interprets this experience and then further shapes our understanding of the original felt experience. Not unlike a dialogical exercise or a conversation, the perceptual and conceptual work in tandem shaping our reality and our ways of knowing.

We have tried to initiate, through a place-based learning experience, such an existential understanding and through the course of this initial journey we have discovered many interesting things. The unlikely pairing of science with physical education has provoked further complexities and challenged many of our own assumptions and understandings. The two disciplines might seem antithetic, and yet they each evoke various perceptual and conceptual capacities. Learning outside the traditional classroom, let alone at a desk, helps dissolve the cultural distinctions between disciplines and the other binary pairs we moderns depend upon in making sense of our world. This demonstrates that disciplines and their subject derivatives are simply metaphors for explaining reality, which invigorate comprehension and appreciation of the earth and world in which we live, a powerful argument substantiating a more integrated curriculum. While exploring outdoors-encountering mystery in the natural world - is integral to Deep Ecology we acknowledge that there are ways for the desk to become more animated and for perceptual ways of knowing to occur within traditional classroom walls. Deep Ecology is of primary interest here but it is spawned by a concern for deep learning. Deep learning is provoked in many ways; mystery and innovative responses (Davis and Simmt 2006) can be encountered through collective and negotiated conversation. As Maturana and Varela (1987) suggest all knowing is doing and all doing is knowing; mystery then can be experienced through the body wherever the body is engaged.

From trees to desks and back again symbolizes our efforts to provide a learning experience founded upon existentialism and within this philosophy the mutual yet dynamic relationship of perceptual (body) and conceptual (mind) capacities. But the phrase could just as easily symbolize a larger divide, that between culture and nature, perhaps the precursor to the binary distinctions of the modern world. Within the culture/nature di- 
chotomy is nested one of the most fundamental binaries, especially of our time: knowledge and mystery. Within academia, our pursuits are driven by and evaluated according to the knowledge we discover often to the detriment and subversion of mystery. And yet each is vital to who we are, how we live with one another, and how we live sustainably with the earth. To the desk and trees and back again evokes the journey of the sojourn and underscores both the necessity and importance of educating in this fashion. We do not reside only in the comfort of our knowledge, but take strides to grapple with mystery and the wonder and awe it evokes. Recall, mystery is the constancy of departure, knowledge the approximation of arrival. The discovery of the mystery of how our knowledge is gifted to us is just as, if not more important, as the very constitution of that knowledge. Such a dynamic evoked by educating between the classroom and the natural world could begin to dissolve those binaries that increasingly structure our world in terms of entities. Dissolution of the entity would go some way toward achieving Deep Ecology as such a philosophical stance avoids other post-modern deconstructions. Perhaps this is the primordial condition Martin Heidegger claimed to be searching for. We have also suggested, by adopting a conceptualization of imagination (Sloan 1983) akin to that of existentialism, that imagination is a capacity necessary to Deep Ecology. Furthermore, learning experiences that engage the imagination take on existential dimensions receptive to Deep Ecology.

Through the activities our students were engaged with and our broader understanding of educating we demonstrate how teacher education could provide the same experiences we desire the students of our teacher candidates to have. It is not enough to simply talk about what is possible. What we envisage must necessarily be experienced through encounters with the natural world, outside the belly of Technicity. This after all is what educare (Jardine 1998) is all about. If it is our desire to cultivate educators who care for children and the earth, we must first care for them.

Furthermore, the pursuit of a deeper, more wholly integrated curriculum begins with and moves beyond a "recovery of the Earth" (Jardine 1998). A recovery of "self," of the whole self, body, mind, heart, and spirit, inclusive of the connections with the Earth, is significant in yielding the possibility of a genuinely integrated curriculum. As Freire (1982) might have suggested, this "recovery" is about becoming more human. In becoming more human, setting aside the stagnant body, we serve students, the oppressed-oppressed not by poverty, race, abuse, or recession alone but, rather, oppressed by the penetrating sting of technological pervasion that has bred a complex strain of indolence. Recovery may entail, a careful listening to our students, listening to the Earth, and listening to our bodies. Once this is understood, teacher candidates might then engage in critical 
discourses that advance self-understanding-body/mind/spirit—-their relationship with the Earth and subsequently provide learning experiences that allow their future students to do the same. After all, this is what Deep Ecology is all about.

\section{Notes}

1. Technicity is a term borrowed from Carol Steiner (1999) denoting a metaphysical epoch. The epoch is a transmutation of Nietzsche's (1883-85/1993) Will to Power and Heidegger's (1962) re-interpretation of ontotheological contemporaneous movements. As metaphysics grounds an age and gives to that age a particular notion of truth, the epoch of Technicity influences, shapes and enframes all constituents of reality. This character of enframing distorts modern subject/ object binary relations to the degree that subjects become objects open to manipulation, control, harnessing and storage. Objects and subjects slowly disintegrate into potential stores of energy redirected upon other subject/object relations (Authors, 2006).

2. Physis according to the Greeks conveyed the two-fold movement of an entity. We moderns translate it as nature, and entirely miss its essence. The dynamic sway of physis implies both capacities of revealing and concealing. Entities are not exhaustively challenged forth as they would be according to contemporary metaphysics, rather the movements of presencing and absencing imply a dynamic relation.

\section{References}

Abram, D. 1996. The Spell of the Sensuous. New York: Vintage Books.

Cheville, J. 2001. Minding the Body: What Student Athletes Know about Learning. Portsmouth, NH: Boynton/Cook.

Cheville, J. 2005. Confronting the problem of embodiment. International Journal of Qualitative Studies in Education, 18(1): 85-107.

Davis, B. and Simmt, E. 2006. Mathematics-for-teaching: An ongoing investigation of the mathematics that teachers (need to) know. Educational Studies in Mathematics, 61(3): 293-319.

Freire, P. 1982. Pedagogy of the Oppressed. New York: Continuum.

Gadamer, H-G. 2002. Truth and Method (2nd rev. ed.; J. Weinsheimer and D. G. Marshall, Trans.). New York: Seabury.

Gardner, H. 1993. Multiple Intelligences: The Theory in Practice. New York: Basic Books.

Giroux, H. A. 1988. Teachers as Intellectuals: Toward a Critical Pedagogy of Learning. Granby, MA: Bergin and Garvey.

Heidegger, M. 1962. Being and Time. (J. Macquarrie and E. Robinson, Trans.). New York: Harper and Row.

Jacobs, J. 2005. Dark Age Ahead. New York: Random House.

Jardine, D. W. 1998. "To dwell with a boundless heart": On the integrated curriculum and the recovery of the earth (1990). In D. W. Jardine (Ed.), To Dwell with 
a Boundless Heart. Essays in Curriculum Theory, Hermeneutics, and the Ecological Imagination (69-84). New York: Peter Lang.

Kamler, B. 2001. Relocating the Personal: A Critical Writing Pedagogy. Albany, NY: State University of New York Press.

Karrow, D. D. 2006. Educating-within-place: Recovering from metaphysics as Technicity. Unpublished doctoral dissertation, The Ontario Institute for Studies in Education of the University of Toronto, Ontario.

Karrow, D. \& Kentel, J. 2005. Educated myopia: Permeating the boundaries of the pre-service teacher training model. Proceedings of the 4 th International Conference on Imagination and Education, Vancouver, BC. http:/ / www.ierg.net/publications/index.html

Kentel, J. 2001. The absence of pedagogy. Ten common practices in elementary physical education and the need for change. PHE Journal, 67(1), 4-9.

Kearney, R. 1998. The wake of imagination. London: Routledge.

Leggo, C. 2004. Living poetry: Five ruminations. Language $\mathcal{E}$ Literacy 6(2), 1-14.

Maturana, H. and Varela, F. 1987. The Tree of Knowledge: The Biological Roots of Human Understanding. Boston: Shambhala.

Merleau-Ponty, M. 1962. Phenomenology of Perception (C. Smith, Trans.). London: Routledge and Kegan Paul.

Meyer, K. 2000. Looking for science in all the wrong places. In C. James (ed.), Experiencing Difference (78-88). Halifax, NS: Fernwood Publishing.

Nietzsche, F. W. 1974. The gay science; with a prelude in rhymes and an appendix of songs. (W. Kaufmann, Trans.) New York: Random House.

Nietzsche, F.W. 1993. Thus Spake Zarathustra. (T. Common, Trans.). Buffalo, NY: Prometheus Books. (Original work published 1883-1885).

Richardson, L. 1992. The consequences of poetic representation: Writing the other, rewriting the self. In C. Ellis and M. Flaherty (eds.), Investigating Subjectivity: Research on Lived Experience (125-140). Newbury Park, CA: Sage.

Saffici, C. 1999. The perceived relevance of physical education. The Physical Educator 56(3): 138-142.

Sawada, D, and Caley, M. 1990. Shibusa: An aesthetic approach to ecosophical education. The Trumpeter: Journal of Ecosophy 7(3): 107-110.

Sloan, D. 1983. Insight-imagination: The Emancipation of Thought and the Modern World. Westport, CT: Greenwood.

Steiner, C. 1999. Constructive science and technological studies: On the path to Being. Social Studies in Science 29(4): 583-616.

Smith, D. G. 1999. Teacher education as a form of discourse: On the relation of the public to the private in conversations about teaching. In D. G. Smith, ed., Pedagon: Interdisciplinary Essays in the Human sciences, Pedagogy and Culture (60-85). New York: Peter Lang.

Thomson, I. 2001. Heidegger on ontological education, or: How we become what we are? Inquiry, 44: 243-268.

Varela, F., Thompson, E., \& Rosch, E. 1991. The embodied mind: Cognitive science and human experience. Cambridge, MA: MIT Press.

Welton, J. 1912. The psychology of education. London: Macmillan.

Whitehead, A. N. 1967. The aims of education and other essays. New York: Free Press. (Original work published 1929). 


\section{About the Authors}

Jeanne Kentel is an assistant professor in the Faculty of Education at Brock University. Her work is informed through the careful mentoring of Dr. Daiyo Sawada, Professor Emeritus of the University of Alberta. She is currently engaged in projects, which examine the significance of deep learning, Deep Ecology, and bodily ways of knowing.

Doug Karrow is assistant professor of science education at the Faculty of Education, Brock University. As a science educator, Doug is keenly aware of the epistemological privilege science is perceived as enjoying. His research focuses on ways to deconstruct modern binaries such as reason/imagination, mind/body, feminine/masculine, and chaos/order and create pedagogical spaces for each to flourish within science education.

(C) Copyright 2007. The authors, Jeanne Kentel and Doug Karrow, assign to the University of Alberta and other educational and non-profit institutions a non-exclusive license to use this document for personal use and in courses of instruction provided that the article is used in full and this copyright statement is reproduced. The authors also grant a non-exclusive license to the University of Alberta to publish this document in full on the World Wide Web, and for the document to be published on mirrors on the World Wide Web. Any other usage is prohibited without the express permission of the authors. 
